\title{
An International Survey and Full-Scale Evacuation Trial Demonstrating the Effectiveness of the Active Dynamic Signage System Concept
}

\author{
Galea, E.R., Xie, H., Deere, S., Cooney, D. and Filippidis, L. \\ Fire Safety Engineering Group \\ The University of Greenwich \\ Park Row, Greenwich, London SE10 9LS, UK
}

\begin{abstract}
Rapid evacuation from large buildings is challenging due to their complex layout making wayfinding difficult. While emergency signage is widely used to aid wayfinding, recent research demonstrates that only $38 \%$ of people perceive conventional exit signs. Furthermore, conventional signage only conveys single and passive information and so cannot adapt to changing conditions. The EU FP7 GETAWAY project addresses this problem through the development of a unique and innovative Intelligent Active Dynamic Signage System (IADSS), which routes occupants to their optimal exits during an evolving incident. This paper presents two key steps in the development of the IADSS concept. First, a novel negated signage concept identifying that an exit route is no longer viable was devised and tested using an international survey. The results demonstrate that the negation concept can be clearly understood by over $90 \%$ of the sample. The second step involved two fullscale evacuation trials in a rail station that demonstrated that it was possible to direct over $60 \%$ of the participants to the targeted exit through the use of the Active Dynamic Signage System (ADSS). The ADSS makes use of the negated signage concept and a development involving a green flashing arrow within the standard emergency exit sign.
\end{abstract}

KEYWORDS: Human Behaviour, Egress, Human Factors, Signage, Dynamic Signage, Wayfinding

\section{INTRODUCTION}

Rapid evacuation from large buildings such as rail and underground stations, airport terminals and shopping malls is often challenging due to the complex layout of these structures making wayfinding difficult. In such circumstances, people often attempt to evacuate via the way they entered the buildings, bypassing or ignoring alternative emergency exits, due to a lack of detailed knowledge of the building layout and situational information [1-3]. While building staff may help manage an evacuation, they cannot be located everywhere throughout the structure and they may not be able to reach the population quickly enough when needed. Managing safe evacuation becomes even more challenging in situations involving a rapidly changing environment, such as may result from a fire or a terrorist lead incident, where it becomes difficult for building staff and the building 
population to maintain an accurate situational awareness and select an optimal evacuation route.

A well-established means of facilitating evacuation within the built environment is the application of emergency signage systems, which are widely used to convey wayfinding information to the building population. However, recent research demonstrates that only $38 \%$ of people perceive the conventional static escape route signs and use them in finding their way out in simulated emergency situations, even if the signs are located directly in front of them and their vision is unobstructed [4]. While not many people perceive the emergency exit sign, the vast majority of people who see the signs follow the information conveyed by the signs. These results suggest that current emergency guidance signs are less effective as an aid to wayfinding than they potentially can be and that signs are likely to become more effective if their detectability can be improved while upholding the comprehensibility of the guidance information they provide. Furthermore, conventional emergency signs normally convey single and passive information; therefore, they cannot adapt to changing conditions and cannot accommodate flexible evacuation options. These limitations in conventional signage systems have contributed to the loss of life in serious fires such as the Kings Cross Underground Station (1988), Düsseldorf airport (1996) and Daegu Jungangno station (2003) fires [5].

The EU FP7 GETAWAY project [6-7] attempted to address these limitations in conventional signage systems through the development of an Intelligent Active Dynamic Signage System (IADSS), which aims to direct building occupants to the optimal exit during an evolving incident. The IADSS consists of an intelligent evacuation route selection support system and an enhanced signage system, the Active Dynamic Signage System (ADSS). The intelligent component of the IADSS, known as the Decision Engine (DE) constantly gathers both the environmental situational information concerning the dispersion of the hazards through the fire detection system and the distribution of the building population through the CCTV system. When an abnormal condition is detected, the DE sends the collected information to the evacuation simulation engine, buildingEXODUS [8]. Based on the situational information, buildingEXODUS performs faster than real time evacuation simulations, running through all of the pre-determined evacuation options and sends the simulation results back to the DE. Using a specially developed algorithm, the DE interrogates the simulation results and ranks the strategies from best to worst based on factors such as projected fatalities and injuries, distance travelled, evacuation time, number of stairs used, etc. The algorithm also provides an estimation of uncertainty for each case. The ranked evacuation strategies are then presented to the human controller who makes the final decision as to which is the best option to implement. The optimal exit route is then indicated to the building population through the ADSS which is activated by the incident controller. The ADSS directs the occupants to their optimal exits and away from non-viable exits. In this paper we discuss the design and testing of the ADSS.

A key component of the ADSS is a novel concept involving incorporating a flashing and running set of LEDs within the sign that highlights the existence of the escape route signs 
within a chain of exit signs leading to the final target exit. The concept of using flashing lights to improve the detectability of emergency exit signs was demonstrated by Jin et al [9]. In a series of experiments they demonstrated that flashing the light source within a lit sign made the sign more conspicuous to test subjects than a standard exit sign of the same size and at the same viewing distance. Nilsson et al $[10,11]$ demonstrated that adding flashing green lights just above an emergency exit made the exit more likely to be used during evacuation trials. Trials involving the use of test subjects in virtual reality environments also suggest that the use of flashing lights above final emergency exits increase the detectability of the emergency exit $[12,13]$ within the virtual test environment and so may also improve detectability in the real world.

In the ADSS the flashing and running set of LEDs is introduced into the standard 'green running man' sign (see Figure 1) to increase the detectability of the signs through enhancing their sensory affordance [3] (based on the Gibson's theory of affordances [14], an affordance is what an object offers the user in relation to the fulfilment of their goal). The sensory affordance is provided by the features of the sign that support people in sensing it and recognising it as an emergency sign; e.g. the green colour of the sign assists people in distinguishing the 'emergency' sign from normal signage. This design maintains the maximum compliance with existing signage regulations $[15,16]$ and does not require any additional fittings (such as external lights). In this way, the conventional static signage system is turned into a dynamic signage system (DSS), while the size and format of the signs and the information conveyed remain unchanged. Furthermore, the concept is intended to be applied to all the emergency exit signs within a signage chain along the escape route, not simply the exit sign located above the final emergency exit. The dynamic nature of the DSS (i.e. the flashing cycle) is only activated during an emergency situation, when the alarm is tripped making the DSS an active DSS or ADSS. The effectiveness of the DSS in improving signage detectability was demonstrated [17-19] under identical experimental settings and conditions as in the previous experiments examining conventional, static signs [4]. The results suggest that $77 \%$ of people 'see' the DSS and $100 \%$ of them go on to follow the sign.

While the DSS concept may be effective in alerting building occupants to the existence of an emergency exit route, a key requirement of the ADSS is the ability to dynamically identify that an exit route is no longer viable. Rather than simply not activating a dynamic sign pointing in the direction of the compromised exit route, it was considered important to convey to the population that a normally viable exit route was no longer considered safe. Thus, exit routes which are considered potentially hazardous are effectively shut down by negating emergency exit signs pointing in those directions. As with the flashing LED concept, it was desirable to develop a negated sign concept which could replace existing signage on a like for like basis, could easily be interpreted by the population without the need for explanation and which would fail safe should it fail to operate. Several potential concepts were considered and tested through an international survey to gauge understanding of the new signage concept. In this paper we present the results of the international survey and identify the best design to represent the negated sign concept. Finally, the effectiveness of 
the ADSS concept is tested and demonstrated through a series of two full-scale trials in a rail station.

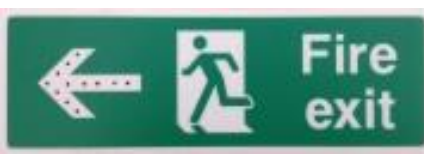

(a)

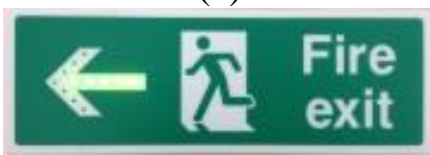

(c)

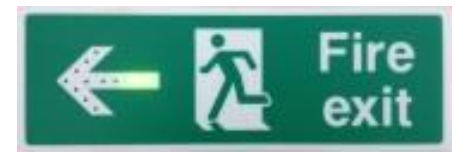

(b)

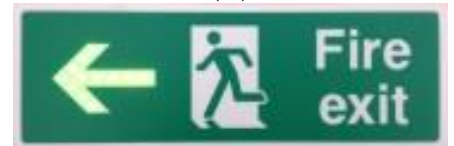

(d)

Figure 1: The ADSS concept implemented within the standard green running man exit sign.

\section{DATA COLLECTION METHODOLOGIES}

The project consisted of two test methodologies, the first was an international survey to identify which negated sign concept was the most easily understood by a naïve population and the second was a full-scale evacuation trial to test the ADSS concept in a realistic application. Both data collection methodologies are described in this section.

\section{THE INTERNATIONAL SURVEY METHOD}

An international web based survey (http://fseg.gre.ac.uk/WhichWay/) was undertaken to gauge the level of understanding amongst the general population of the proposed negated signage concept and to identify which design would be selected for incorporation within the ADSS. The survey examined four potential designs of negated sign (see Figure 2) in order to determine which design, if any, conveyed the clearest indication that the exit route originally indicated by the sign was no longer considered viable. The four options were selected as they were considered to be the easiest to incorporate within the existing emergency sign. The survey questions addressed three issues in the following order: signage interpretation, ranking level of agreement with the specified meaning and identifying which of the four options most clearly suggests that the exit route is not available. As part of the survey, respondents were asked to identify their profession. The replies to the various tasks were separated into replies from fire professionals, non-fire professionals and the overall sample. This was done to ensure that the results were not biased by the opinions of the fire professionals who are expected to have a greater appreciation of emergency signage.

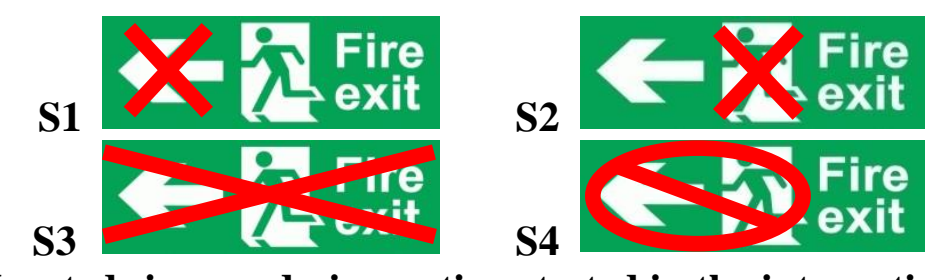

Figure 2: Negated signage design options tested in the international survey. 
1) Signage interpretation: Each potential design was shown to the participants, without providing an indication of what the sign was intended to represent. The participants were then asked to write down what they thought the sign meant. The interpretation of each sign was independently assessed by two different assessors as either correctly or incorrectly interpreting the intended meaning of the sign.

2) Ranking level of agreement with the specified meaning: Each potential design was shown to the participants again along with a sentence describing the intended meaning of the sign. The participants were then asked to rate how strongly they agreed with the provided interpretation. The level of agreement was based on a five point Likert scale, ranging from strongly disagree to strongly agree. The descriptive sentence that was asked for each sign was:

"The sign shown below clearly suggests to me that the emergency exit route is no longer available for use."

3) Identifying which option most clearly suggests that the exit route is not available: All four variants were shown to the participants at the same time and they were asked to identify which one most clearly indicates that the exit route is no longer available.

The preliminary analysis, completed by 19 May 2012, was primarily used to identify which design would be selected for incorporation within the ADSS. The preliminary results (reported in [18]) were based on the responses from 457 participants (74\% males and 25\% females) from more than 10 countries (the preliminary data-set in Table 1). The survey remained active and an additional $156(34 \%)$ participants completed the survey by 30 January 2015. In total 613 people ( $74 \%$ males and $25 \%$ females) have completed the survey (the complete data-set in Table 1). The findings from the complete data-set are presented in this paper and represent the conclusive results of the survey.

Table 1: Profession, age and country of the respondents.

\begin{tabular}{|c|c|c|c|c|c|c|c|c|c|c|c|c|}
\hline \multirow[b]{2}{*}{$\begin{array}{l}\text { Data-Set* } \\
\text { (number) }\end{array}$} & \multicolumn{2}{|c|}{ Profession } & \multicolumn{3}{|c|}{ Age } & \multicolumn{7}{|c|}{ Country } \\
\hline & Fire Prof & $\begin{array}{l}\text { Non-fire } \\
\text { Prof }\end{array}$ & $\begin{array}{c}\text { Age } \\
15-25\end{array}$ & $\begin{array}{c}\text { Age } \\
26-50\end{array}$ & $\begin{array}{c}\text { Age } \\
51-75\end{array}$ & UK & Germany & France & Italy & China & USA & Others \\
\hline $\begin{array}{c}\text { Preliminary } \\
\text { (457) }\end{array}$ & $\begin{array}{c}246 \\
(54 \%)\end{array}$ & $\begin{array}{c}206 \\
(45 \%)\end{array}$ & $\begin{array}{c}139 \\
(30 \%)\end{array}$ & $\begin{array}{c}212 \\
(46 \%)\end{array}$ & $\begin{array}{c}99 \\
(22 \%)\end{array}$ & $\begin{array}{c}143 \\
(31 \%)\end{array}$ & $\begin{array}{c}94 \\
(21 \%)\end{array}$ & $\begin{array}{c}26 \\
(6 \%)\end{array}$ & $\begin{array}{c}21 \\
(5 \%)\end{array}$ & $\begin{array}{c}40 \\
(9 \%)\end{array}$ & $\begin{array}{c}70 \\
(15 \%)\end{array}$ & $\begin{array}{c}63 \\
(14 \%)\end{array}$ \\
\hline $\begin{array}{c}\text { Complete } \\
(613)\end{array}$ & $\begin{array}{c}322 \\
(53 \%)\end{array}$ & $\begin{array}{c}286 \\
(47 \%)\end{array}$ & $\begin{array}{c}176 \\
(29 \%)\end{array}$ & $\begin{array}{c}298 \\
(49 \%)\end{array}$ & $\begin{array}{c}132 \\
(22 \%) \\
\end{array}$ & $\begin{array}{c}203 \\
(33 \%) \\
\end{array}$ & $\begin{array}{c}119 \\
(19 \%)\end{array}$ & $\begin{array}{c}32 \\
(5 \%) \\
\end{array}$ & $\begin{array}{c}41 \\
(7 \%)\end{array}$ & $\begin{array}{c}43 \\
(7 \%)\end{array}$ & $\begin{array}{c}82 \\
(13 \%) \\
\end{array}$ & $\begin{array}{c}93 \\
(15 \%) \\
\end{array}$ \\
\hline
\end{tabular}

* Not everyone answered all questions.

\section{THE EXPERIMENTAL TRIAL METHOD}

The ADSS concept tested in the trials consisted of the flashing green led arrow signage design (initial concept tested through the laboratory trials [17-19]) and the negated signage design (utilising the design identified through the international survey described in previous section). The effectiveness of the ADSS concept was then tested through a full-sale evacuation trial within a rail station environment. The results were compared with that of a similar evacuation trial but using the conventional escape route signage system. 
The trials were designed to investigate how people react to and utilise each of the two signage systems to find their way out of an unfamiliar environment in a presumed emergency situation, without staff intervention. The first trial measured how the participants performed using the standard escape route signage system, while the second trial measured the performance of the participants when guided by the ADSS. The two full scale evacuation trials used two different groups of people, with similar demographics. The design of the trials assumes that signage systems can influence evacuee performance and the type of signage used is a factor in this influence.

The trials took place at the Sant Cugat station in Barcelona, Spain. The trials involved one platform (Platform 2) of the station that was occupied only by the trial participants. The platform is approximately 38 metres long and has four exits (Exit A to D) from left to right (see Figure 3). Exit A and Exit D lead out of the station onto a public road. Exit B and Exit C are entrances to the underpass which leads to the main entrance on the other side of the station. Exit B is an elevator which would not normally be used as part of an evacuation but was an exit point. The trials assumed that an incident had occurred that requires the immediate evacuation of the station.

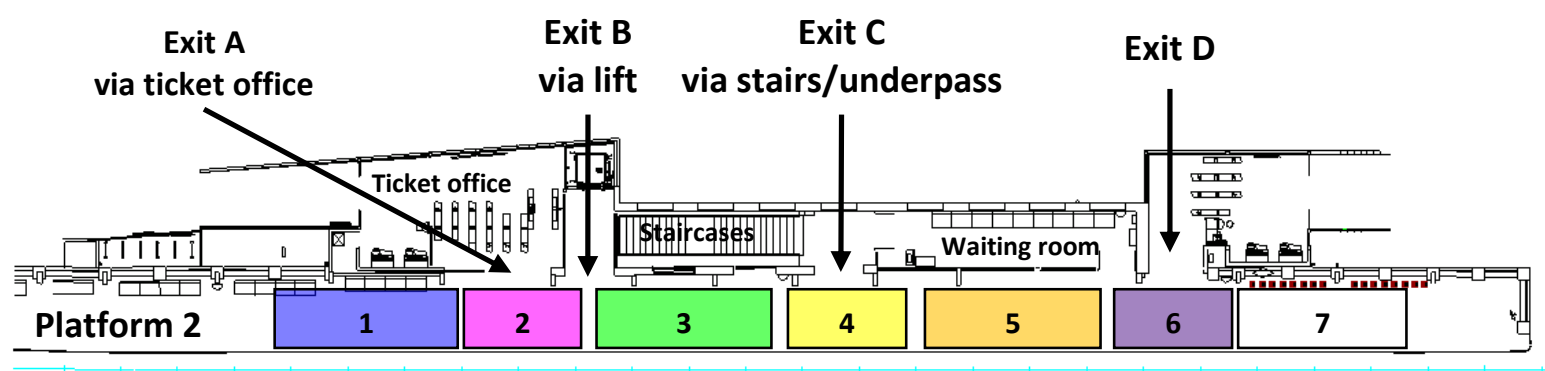

\section{Figure 3: Layout of Platform 2 of the Sant Cugat station and 7 boxes used to distribute the participants.}

To ensure that the conditions in both trials were identical, participants were located in each of seven staging boxes located along the platform (see Figure 3 ). The population density within the boxes was approximately the same in each box and in each trial and representative of conditions during peak station usage $\left(2\right.$ persons $\left./ \mathrm{m}^{2}\right)$. To achieve this, some 200 participants were required for each trial. Ferrocarrils de la Generalitat de Catalunya (FGC) - the operator of the rail system in Barcelona - recruited the participants from the local area using adverts at their stations, on their website, social networks and local media. A total of 700 volunteers registered their interest in attending the trials. These volunteers were then selected according to the trial requirements, which included limited knowledge of the trial station and the demographics resembling typical FGC travellers, to produce the final participant population. While the demographics of the trials was planned and partially controlled through the selection process, the actual demographics of the populations used in the trials was governed by the number and nature of people that actually showed up on the trial days. Approximately $36 \%$ of the invited participants failed to show up on each day. For a discussion of the trial demographics please see sub-section 1 of the trial results. To compensate participants for 
incurred travel costs, they could select one of two forms of compensation consisting of a small cash payment or free rail and entry tickets to an FGC tourist attraction on completing the trials and questionnaires.

On the day of each trial, the participants gathered at a nearby station and were briefed about the trial but were given no specific information concerning the signage systems or the purpose of the trials. The participants were taken to the trial station by train and distributed on the platform at specific locations identified by the seven numbered (and coloured) boxes on the platform (see Figure 3) - thus the participants did not experience using any of the exits prior to the trial. The participants were positioned to face the track as if they were waiting for the next train and waited until the start of the trial which was signified by the sounding of the fire alarm. The fire alarm was a voice alarm with a tone followed by a message instructing the participants that there is an emergency and they should leave the station immediately. This sequence was constantly repeated throughout the trial.

Platform 2 was then evacuated. The routes adopted by the evacuating population during each trial were recorded using video cameras for later analysis. On completion of the trials the participants were given a questionnaire that was designed to collect information regarding participant exit choice, the factors influencing their decision and their opinions concerning the signs they encountered during the trials. The data derived from the video footage and the completed questionnaires were cross-referenced where possible in order to increase the credibility of the findings.

The first trial, TS2.1, conducted on the $26^{\text {th }}$ May 2013, was intended to establish a baseline response to a conventional escape route signage system. During TS2.1, standard EC directive 92/58/EEC-compliant exit signs were used (see Figure 4a). These signs are referred to in the rest of this paper as 'static' signs. All of the signs pointed directly towards the nearest exits (see Figure 5). A total of 139 participants (counted from video footage however, it is noted that 149 questionnaires were returned) eventually took part in TS2.1, the shortfall in the number of participants was accommodated by reducing the number of participants within each box area so that the density within each box was approximately the same.

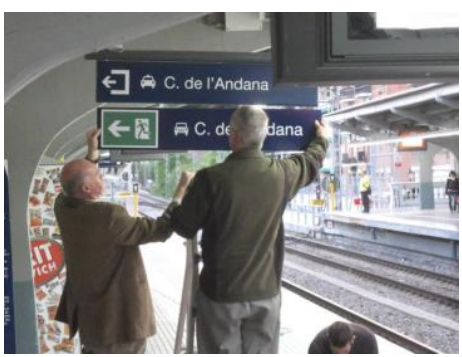

(a)

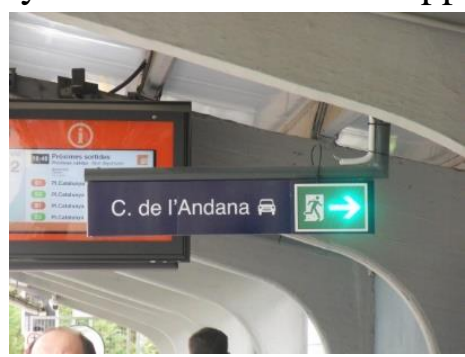

(b)

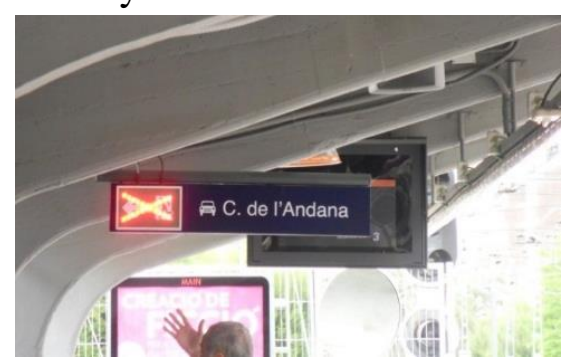

(c)

Figure 4: (a) The standard static exit sign, (b) the ADSS with flashing and running green arrow and (c) the ADSS with negating flashing red cross.

The second trial, TS2.2, consisting of 152 participants (counted from video footage), conducted one week later on the $2^{\text {nd }}$ June 2013, was to assess the participant reaction to the ADSS (see Figure $4 b$ and $4 c$ ), which was activated at the same time as the alarm during the 
trial. The ADSS was configured to direct all participants towards an intended exit, Exit D located at one end of the platform, according to a specific evacuation strategy (see Figure 5). This was not the nearest exit for the majority of the participant population and therefore required them to adopt a different behaviour from that exhibited in the first trial. As a result, the ADSS was configured so that the signs over exits $\mathrm{A}, \mathrm{B}$ and $\mathrm{C}$ would display the flashing red cross, indicating that these exits should not be used, while the sign over exit D displayed the flashing running green arrow, indicating that this was the exit that should be used. The only intended difference in the trial procedure between the two trials was the signage systems employed (see Figure 5).

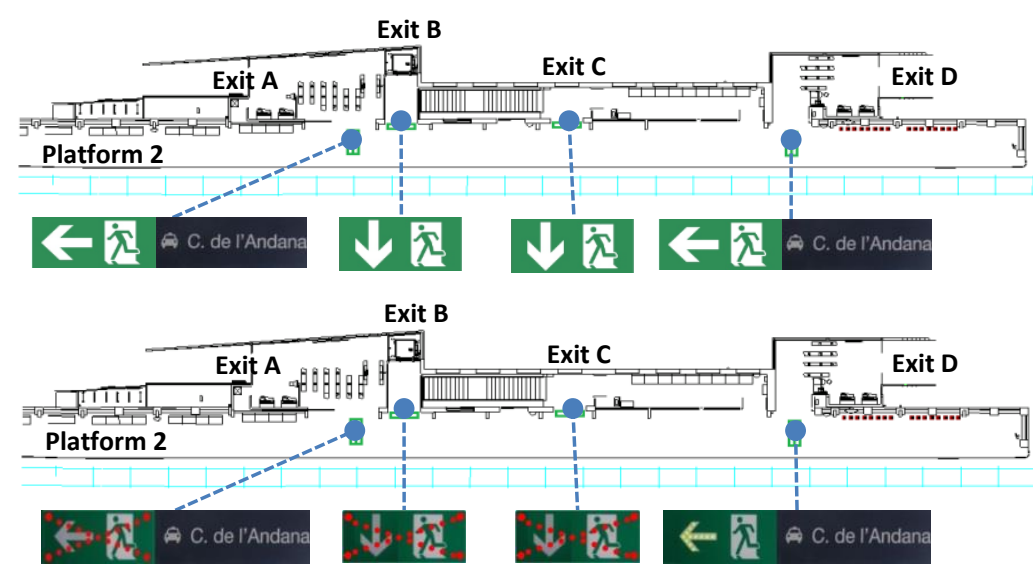

Figure 5: Deployment of the standard signage system in the first trial (top) and the ADSS in the second trial (bottom) on the trial platform.

It should be noted that, unlike the laboratory studies which examined the individuals' interaction with the DSS in relatively ideal conditions [17-19], during the two full scale evacuation trials there were more influencing factors that potentially had an impact on the participants' exit route/exit selection. These included the surrounding population's actions, the participant's level of familiarity with the platform layout, their initial location on the platform and the presence of the signs. In addition, there was the apparent affordance provided by the immediate openings on the platform (i.e. Exits $\mathrm{A}, \mathrm{B}$ and $\mathrm{C}$ ) as a clear indication of a possible way out to the participants. The presence of these multiple influencing factors could complicate the examination of the influence of the signage systems in the trials.

Data was collected using video cameras mounted to the ceiling of the canopy of the platform and a post-trial questionnaire. The post-trial questionnaire was mainly used to gain an understanding of the participants' exit route/exit selection and, in particular, identify the factors that influenced them in making this selection during the evacuation. The questionnaire consisted of 12 high-level closed questions, leading to more probing (although still closed) sub-questions in several instances. The questionnaire was written in English and then translated into Catalan by FGC. The analysis of the video footage enabled the identification of the primary factors in the trials, such as the number of participants starting in each numbered box on the platform, moving to each exit and the time to evacuate the platform. 
The video analysis also enabled the identification of the secondary factors to some extent, such as the number of participants observed looking up at the signs during their movement, following other participants and engaging in group behaviour. The secondary factors were collected in support of the results collected from the questionnaire. These results also enabled some understanding of what actions were performed and what factors influenced the selection of exit routes/exits.

It is noted that an independent ethics review of the trial design was carried out by the University of Greenwich independent Research Ethics Committee to ensure that the proposed trials met recognised ethical standards for conducting trials with members of the public and for the collection, analysis and handling of personal data.

\section{RESULTS OF INTERNATIONAL SURVEY CONCERNING NEGATED SIGNAGE DESIGN}

The results of the international survey concerning the negated signage design are presented and discussed in this section. The results represent the findings from the complete data-set.

1) Signage Interpretation: The correct interpretation of the four negated signs is that the exit route originally indicated by these signs was no longer considered viable. The percentage of respondents who correctly interpreted the meaning of each sign is presented in Table 2. Note that not all the 613 respondents answered all the questions, and a small number of respondents were also excluded as they provided what was considered to be farcical responses. It is noted that the results presented in Table 2 that the conclusions derived from the smaller preliminary data-set are supported by the later larger complete data-set. It is also noted that there are only small differences between the level of understanding shown by the fire safety professional community and the other professions.

Table 2: Percentage of respondents who correctly interpreted meaning of signs.

\begin{tabular}{|c|c|c|c|}
\hline Exit signs based on negated signage design & Fire safety profession & Other professions & Total \\
\hline Exit & $\begin{array}{c}83 \% \\
(312 \text { total })\end{array}$ & $\begin{array}{c}85 \% \\
(275 \text { total })\end{array}$ & $\begin{array}{c}84 \% \\
(587 \text { total })\end{array}$ \\
\hline Fire & $\begin{array}{c}63 \% \\
(311 \text { total })\end{array}$ & $\begin{array}{c}52 \% \\
(268 \text { total })\end{array}$ & $\begin{array}{c}58 \% \\
(579 \text { total })\end{array}$ \\
\hline S3 & $\begin{array}{c}92 \% \\
(311 \text { total })\end{array}$ & $\begin{array}{c}92 \% \\
(270 \text { total })\end{array}$ & $\begin{array}{c}(581 \text { total }) \\
\text { S4 }\end{array}$ \\
\hline
\end{tabular}

Clearly, sign S3 with the large red cross achieved the highest level of understanding, with 92\% of the sample providing the correct interpretation. This compares with only $58 \%$ correct interpretation for the poorest performing sign (red cross over the running man $-\mathrm{S} 2$ ). It is 
interesting to note that the symbol generally taken to mean negation (circle with the slash S4) provided the second lowest correct interpretation (76\%).

Examples of common correct interpretations provided by the participants include:

There is no fire exit in the left direction.

Fire exit to left not available (without any doubt!).

Fire exit to the left is out of action/damaged or taken out of use.

I would interpret this sign to mean that the exit is unavailable.

It is also informative to view some common incorrect interpretations for the signs. For the sign with the red cross over the arrow (S1), incorrect responses included:

Go through the door, but don't go in the direction of the arrow.

Fire exit is here but not to the left.

No clue.

Here is the fire exit, next path is closed.

The sign that had the poorest comprehension was the sign with the red cross over the running man (S2). This sign appeared to cause the greatest confusion amongst all the participants fire professionals and non-fire professionals alike. Many people suggested that this meant that you should not run to the exit. Another common missinterpretatoin was that this meant that the exit was not appropriate for people. Other incorrect responses included:

This sign is ambiguous.

Have no idea.

Ignore this sign.

Nonsense, if there is a fire exit and I should not go through the door what else should

I do? Fly?

For the sign with the circle with slash (S4), a common response was that the participant was confused and didn't know what the sign meant, e.g.

Confusing.

Sign is broken.

Not sure.

It has no meaning in my opinion.

No idea.

Finally, the sign with the large red cross through the entire sign (S3), with a 92\% understanding rating was correctly interpreted by most people; however, some suggested that it could mean that the sign is no longer in use. Other incorrect interpretations included:

Don't exit the building.

Sign is out of order.

The sign is meaningless. 
2) Ranking level of agreement with the specified meaning: The results from the ranking of the level of agreement with the statement are presented in Table 3. Note that the fifth point of the likert scale not presented in Table 3 is the neutral option of 'Neither Agree nor Disagree'.

Table 3: Respondents' level of agreement with the statement regarding the intended meaning of the negated signs.

\begin{tabular}{|c|c|c|}
\hline Exit signs based on negated signage design & Agree & Disagree \\
\hline S> Pre & $\begin{array}{c}\mathbf{5 3 \%} \\
(17 \% \text { strongly agree and } \\
36 \% \text { agree })\end{array}$ & $\begin{array}{c}\mathbf{3 8 \%} \\
(14 \% \text { strongly disagree and } 24 \% \\
\text { disagree })\end{array}$ \\
\hline S2 & $\begin{array}{c}\mathbf{4 3 \%} \\
(13 \% \text { strongly agree and } \\
30 \% \text { agree }) \\
\end{array}$ & $\begin{array}{c}\mathbf{4 2 \%} \\
(15 \% \text { strongly disagree and } \\
27 \% \text { disagree }) \\
\end{array}$ \\
\hline & $\begin{array}{c}\mathbf{8 4 \%} \\
(54 \% \text { strongly agree and } \\
30 \% \text { agree })\end{array}$ & $\begin{array}{c}\mathbf{1 0 \%} \\
(6 \% \text { strongly disagree and } \\
4 \% \text { disagree })\end{array}$ \\
\hline S4 & $\begin{array}{c}\mathbf{4 4 \%} \\
(15 \% \text { strongly agree and } \\
29 \% \text { agree })\end{array}$ & $\begin{array}{c}\mathbf{3 9 \%} \\
(13 \% \text { strongly disagree and } \\
26 \% \text { disagree) }\end{array}$ \\
\hline
\end{tabular}

The sign with the large red cross through the entire sign (S3) had by far both the greatest level of agreement with the statement and the smallest level of disagreement with the statement. The S3 sign had almost twice the level of agreement as the other signs. For the other signage concepts, even once the correct interpretation was suggested, significant numbers disagreed with the interpretation. This indicates that signage concepts S1, S2 and S4 are not only not intuitive (result of question 1), they also appear not to be logical to a large proportion of the population.

3) Identifying which option most clearly suggests that the exit route is not available: The overwhelming majority of the respondents (85\%) selected sign S3 (see Table 4). Given the results of the previous two questions, it is not surprising that the vast majority of the participants thought that signage option S3 provided the clearest indication that the emergency exit route was not available.

Table 4: Percentage of respondents who identified which one of the four negated signs best denoted the concept that the exit route was no longer viable.

\begin{tabular}{|c|c|}
\hline Exit signs based on negated signage design & Percentage of population \\
\hline s1 & $\begin{array}{l}7 \% \\
(41)\end{array}$ \\
\hline $\begin{array}{l}\text { Fire } \\
\text { exit }\end{array}$ & $\begin{array}{l}3 \% \\
(16)\end{array}$ \\
\hline pivitive & $\begin{array}{l}\mathbf{8 5 \%} \\
(514)\end{array}$ \\
\hline S4 & $\begin{array}{l}\mathbf{5 \%} \\
(31)\end{array}$ \\
\hline
\end{tabular}


As noted earlier, while the analysis of the preliminary survey results (reported in [18]) were used to inform the design of the negated sign that was incorporated within the ADSS and used in the trials, the results from the complete survey confirm the earlier findings. Thus, from the analysis of the preliminary and complete survey results, it is clear that the negated signage design which has the best interpretation, recognition and appears to be most logical is the sign with the large red cross through the entire sign (S3). This negated signage design was therefore adopted in the development of the ADSS. A prototype dynamic sign that incorporated both the flashing arrow and the large red cross was developed for further testing in the GETAWAY project (see Figure 6). During an evacuation, if the exit route indicated by the sign is considered to be non-viable, the red cross will be activated; otherwise, the flashing arrow will be actived (see Figure 1). When the red cross is activated, the majority of red LEDs in the cross are static and, once the sign is activated remain on throughout the evacuation. However, the first and last LEDs in the cross on the left and right side flash alternatively, drawing attention to the sign. The reason that the entire red cross does not flash is so as not to potentially confuse the observer into incorrectly thinking that the sign may be malfunctioning. This negated sign concept was tested in the full-scale evacuation trial (reported in this paper) conducted at a rail station in Barcelona, Spain in 2013.

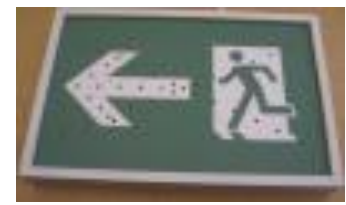

(a)

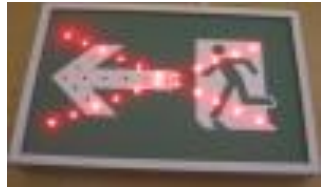

(c)

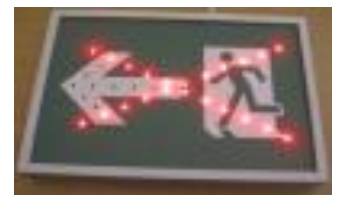

(b)

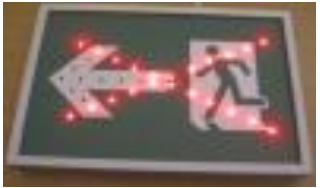

(d)

Figure 6: The ADSS implemented within the green running man signage concept demonstrating route negation.

\section{EXPERIMENTAL RESULTS AND DISCUSSION}

An analysis of the participant population demographics is first presented in subsection 1 . Following this an analysis of social relationships/potential group behaviour and participant familiarity with the layout is presented in subsections 2 and 3 respectively. Finally, the results of the two full-scale evacuation trials TS2.1 and TS2.2 from two data sources (video footage and post-trial questionnaire) are presented and discussed in subsections 4 to 6 .

\section{1) Demographics of participant population}

The demographics of the participant populations attending the two trials is derived from the questionnaire data (see Table 5 and Table 6). It can be seen that the two populations are broadly similar in age and gender distribution. Given the original desired population specification, the two populations are assumed to be broadly representative of typical FGC travellers in terms of demographic distribution. 
Note that there were 149 questionnaires completed after TS2.1. However, only 139 participants were identified and counted in the video analysis. It is unclear how this discrepancy occurred. It may be due to an inability of the video cameras to capture overlapped participants given the restrictions in positioning the cameras on the platform. The two numbers are used separately in the following video and questionnaire analysis and are cross-referenced where necessary.

Table 5: Age distribution of trial participants and the intended age distribution.

\begin{tabular}{|c|c|c|c|c|c|}
\hline \multirow{2}{*}{ Age } & \multicolumn{2}{|l|}{$\begin{array}{r}\text { TS2.1 } \\
\end{array}$} & \multicolumn{2}{|l|}{$\begin{array}{r}\text { TS2.2 } \\
\end{array}$} & \multirow{2}{*}{$\begin{array}{l}\text { Intended age } \\
\text { distribution }\end{array}$} \\
\hline & Number of participants & Percentage & Number of participants & Percentage & \\
\hline $18-20$ & 11 & $7.4 \%$ & 5 & $3.3 \%$ & $10 \%$ \\
\hline $20-29$ & 39 & $26.2 \%$ & 43 & $28.3 \%$ & $20 \%$ \\
\hline $30-49$ & 69 & $46.3 \%$ & 78 & $51.3 \%$ & $45 \%$ \\
\hline $50-59$ & 16 & $10.7 \%$ & 18 & $11.8 \%$ & $15 \%$ \\
\hline$>=60$ & 14 & $9.4 \%$ & 8 & $5.3 \%$ & $10 \%$ \\
\hline Total & 149 & $100.0 \%$ & 152 & $100.0 \%$ & $100 \%$ \\
\hline
\end{tabular}

Table 6: Gender distribution of trial participants and the intended gender distribution.

\begin{tabular}{|c|c|c|c|c|c|}
\hline \multirow{2}{*}{ Gender } & \multicolumn{2}{|l|}{ TS2.1 } & \multicolumn{2}{|l|}{ TS2.2 } & \multirow{2}{*}{$\begin{array}{c}\text { Intended gender } \\
\text { distribution }\end{array}$} \\
\hline & Number of participants & Percentage & Number of participants & Percentage & \\
\hline Male & 74 & $49.7 \%$ & 84 & $55.3 \%$ & $55 \%$ \\
\hline Female & 75 & $50.3 \%$ & 68 & $44.7 \%$ & $45 \%$ \\
\hline Total & 149 & $100.0 \%$ & 152 & $100.0 \%$ & $100 \%$ \\
\hline
\end{tabular}

Apart from the demographic distribution, the two trial populations are also similar in all the other aspects, including the distribution of participants' occupation, participant impairment present during the trials, their level of familiarity with the station and exit awareness.

In both trials about one fifth of the participants are unemployed or retired, another one fifth of the participants are students and the others are employed. More importantly, there were no FGC staff participating in either of the trials. This is particularly important as the participation of staff members would have affected the degree of familiarity in the population which, in turn, could have affected their exit selection. The nature of the trials required participants to be able to receive acoustic and visual information as well as being able to navigate the FGC station, including stairs, without assistance from others. The questionnaire data confirms that the vast majority of the participants of both trials had no impairments that affected their ability to conduct the trials.

Of the participant populations, $44.3 \%$ in TS2.1 and $44.7 \%$ in TS2.2 were unfamiliar with the station (i.e. never used), while $45.0 \%$ in TS2.1 and $47.4 \%$ in TS2.2 were infrequent (used the station less than once or twice per month) users of the station (see Table 7). In effect, the vast majority (approximately 90\% in both trials) were, at most, infrequent users of the station and so would not necessarily be familiar with the station layout. The exit awareness among the participants in the two trials was also broadly similar. A small minority of participants knew of only one exit (4.7\% in TS2.1 and 7.3\% in TS2.2), while the vast majority of participants knew of multiple exits among which they had to make a selection during the trials. 
Table 7: Participant familiarity with the trial geometry.

\begin{tabular}{|c|c|c|c|c|}
\hline \multirow{2}{*}{ Frequency } & \multicolumn{2}{|c|}{ TS2.1 } & \multicolumn{2}{c|}{ TS2.2 } \\
\cline { 2 - 5 } & Number of participants & Percentage & Number of participants & Percentage \\
\hline Never & 66 & $44.3 \%$ & 68 & $44.7 \%$ \\
\hline $1-7$ days/week & 5 & $3.4 \%$ & 6 & $3.9 \%$ \\
\hline 1 or 2/month & 11 & $7.4 \%$ & 6 & $47.9 \%$ \\
\hline $\begin{array}{c}\text { Infrequently (i.e. less than } \\
1 \text { or 2/month) }\end{array}$ & 67 & $45.0 \%$ & 72 & $100.0 \%$ \\
\hline Total & 149 & $100.0 \%$ & 152 & 4 \\
\hline
\end{tabular}

\section{2) Social relationships and participant grouping behaviour}

People who have social relationships (e.g. family, friends) tend to stay and move together during an evacuation. How some participants might form a group and evacuate together during the trials was examined through both questionnaire and video analysis. The results of questionnaire analysis show that $38.3 \%$ of the participant population in TS2.1 and $32.9 \%$ in TS2.2 started evacuation in a group of mostly familiar others (72\% of whom were colleagues, family members and friends). Among these participants, the vast majority claimed that they exited the station with some and all group members. More than half of them also claimed that their groups had more than 10 people. These results suggested that several large groups of participants were formed and most people in these groups were moving together during the trials. However, given the trial procedure, i.e. the participants were randomly selected and mixed to fill the seven boxes on the platform, it was unlikely that the participants would happen to form large groups of family/friends when they were waiting in these boxes. In addition, when the trials started, there were only a few people who were observed on the video footage to deliberately join with others; i.e. who sought out those that they appeared to know. No other evidence was found in video analysis indicating that people regrouped into several large groups of familiar others and then moved together. Therefore, it is highly likely that the majority of the participants interpreted "group" in the questionnaire as the surrounding population in each box area rather than as representing familiar others. This may have been due to a translation issue associated with the interpretation of the word 'group'.

\section{3) Impact of familiarity with station layout on exit selection}

The participants' level of familiarity with the station layout is a factor that could potentially influence their choice of exit in the trials - based on the assumption that people tend to move towards the familiar exit. To minimise the influence of this factor (i.e. biasing participants' exit choice), it was planned that Participants should not be frequent users of the station and should not have participated in prior GETAWAY trials.

Ideally, all participants should not have used the FGC Sant Cugat station prior to the trials. However, from the questionnaire results it is noted that $44.3 \%$ in TS2.1 and $44.7 \%$ in TS2.2 were completely unfamiliar with the station, while the rest of the population had some level of familiarity with the station (see Table 7). While the number unfamiliar with the station in the trial is likely to be higher than would be expected in a real station, it was not as high as planned and prevented the familiarity being completely controlled during the trials. It is 
however noted that the bulk of the participants that are classed as familiar only make use of the station once or twice per month and so are not considered to have significant knowledge and familiarity of the station layout. Furthermore, the frequency distribution of the participants' previous use of the station is almost identical between the two trials. How the unfamiliar participants and familiar participants might behave differently in exit selection was further examined by considering their initial positions on the platform. The numbers of unfamiliar and familiar participants in each box are listed in Table 8. It can be seen that there was a mix of unfamiliar and familiar participants across all the boxes in the two trials. As a result it is expected that the influence of the level of familiarity, if any, should at least be similar during the two trials and geographically similar within each trial.

Table 8: The numbers of unfamiliar and familiar participants positioned in the seven boxes in the trials.

\begin{tabular}{|c|c|c|c|c|c|c|c|c|c|}
\hline \multicolumn{2}{|c|}{} & Blue/1 & Magenta/2 & Green/3 & Yellow/4 & Orange/5 & Purple/6 & White/7 & Total \\
\hline \multirow{2}{*}{ TS2.1 } & Unfamiliar & 8 & 9 & 10 & 10 & 9 & 11 & 9 & \multirow{2}{*}{149} \\
\cline { 2 - 10 } & Familiar & 16 & 4 & 18 & 8 & 16 & 4 & 17 & \\
\hline \multirow{2}{*}{ TS2.2 } & Unfamiliar & 10 & 8 & 11 & 5 & 15 & 6 & 13 & \multirow{2}{*}{152} \\
\cline { 2 - 9 } & Familiar & 21 & 13 & 14 & 6 & 12 & 7 & 11 & \\
\hline
\end{tabular}

Given the participants' level of familiarity with the station and their location on the platform, it is important to know whether the participants, especially those who have used the station before, had any preference for a particular exit. This was examined through the participants' exit selection in TS2.1, assuming the affordance provided by the standard signage system to all three viable exits was the same. The video analysis shows that $99 \%$ of the participants in TS2.1 used their nearest exit. Therefore, it was expected that none of the exits appeared more preferable than the others to the extent that it overcame issues of proximity.

\section{4) Results of TS2.1 from video analysis - Standard Signage System}

Trial TS2.1 was intended to provide a baseline indication of the exit routes used. This trial involved the use of standard emergency exit signs to direct the participants towards all available exits. In effect, this would have been the expected route use had there not been any environmental cues, staff intervention or other procedural measures (including dynamic signage) present to influence performance, apart from the standard signage system. The behaviour exhibited in TS2.2 (where the difference is the introduction of the ADSS into the evacuation procedure) can then be compared to that in TS2.1, particularly the exit use.

The video analysis of TS2.1 involved 139 participants. Presented in Table 9 are the number of participants that started in each of the numbered boxes and then used one of the three exits (Exits A, C and D) during TS2.1. The number of participants from each numbered box who moved to their nearest exit is highlighted in bold. It was observed that 99\% (137 out of 139 participants) of the population moved to their nearest exit; i.e. with no other attempt to redirect people to alternative exits, people typically made use of their nearest exit. It is 
unclear from the video footage why two participants from the Yellow box travelled along the platform to an alternative exit.

Table 9: Starting and ending locations of participants during TS2.1.

\begin{tabular}{|c|c|c|c|c|c|c|c|c|c|}
\hline \multirow{2}{*}{ Exit used } & \multicolumn{7}{|c|}{ Boxes and initial population size } & \multirow{2}{*}{ Total } & \multirow{2}{*}{$\begin{array}{c}\text { moved to } \\
\text { each exit }\end{array}$} \\
\cline { 2 - 10 } & Blue/1 & Magenta/2 & Green/3 & Yellow/4 & Orange/5 & Purple/6 & White/7 & \\
\cline { 2 - 9 } & 21 & 12 & 24 & 19 & 26 & 14 & 23 & 139 & \\
\hline Exit A & $\mathbf{2 1}$ & $\mathbf{1 2}$ & $\mathbf{2 3}$ & 0 & 0 & 0 & 0 & 56 & $40.3 \%$ \\
\hline Exit C & 0 & 0 & $\mathbf{1}$ & $\mathbf{1 7}$ & $\mathbf{5}$ & 0 & 0 & 23 & $16.5 \%$ \\
\hline Exit D & 0 & 0 & 0 & 2 & $\mathbf{2 1}$ & $\mathbf{1 4}$ & $\mathbf{2 3}$ & 60 & $43.2 \%$ \\
\hline
\end{tabular}

A total of 56 participants used Exit A with the last participant exiting after 33 seconds, 23 participants used Exit $\mathrm{C}$ with the last participant exiting in 29 seconds and 60 participants used Exit D with the last participant exiting in 45 seconds. The entire platform was then cleared within 45 seconds. Clearly, there was an even usage of Exit A and Exit D at either end of the platform with far fewer participants opting to use the central exit (Exit C). This distribution of exit use may be attributed to the positioning of the numbered boxes whereby only box 4 (Yellow box) is near the central exit and only a few participants in boxes 5 and 3 (Orange and Green boxes respectively) were closer to the central Exit $\mathrm{C}$ than the outer Exit A and Exit D.

Although several video cameras were placed to monitor the trial (mostly to record the number of participants using each exit), some cameras viewed the back of the participants, making it difficult to observe and therefore definitively establish their actions at certain locations. Given this restriction, it was difficult to determine from the video footage, with certainty, the number of participants who made use of the emergency signage during TS2.1. As a result, the signage usage estimated from the video footage should be considered a conservative estimate. A more reliable estimate can be derived from the questionnaire response. From the video footage, only $5 \%$ of the population were observed looking up at the emergency signage ( 7 out of 139 participants); i.e. 5\% were seen to deliberately examine the emergency signs available, although from the video footage it was not possible to establish whether this information was then used. The seven participants who were observed looking up at the emergency signage were located in the numbered boxes next to the exits: two in box 3 (Green), three in box 4 (Yellow) and two in box 6 (Purple). No participants initially located in boxes 1 and 2 (Blue and Magenta) were observed looking at the signs. This was influenced by (1) the camera location making it particularly difficult to establish participant activities, and (2) that these participants had to walk further than those in the other boxes in order to exit the platform, potentially giving them more time to establish exit locations.

It was noted that the participants were standing on the platform for several minutes before the trial started and so may have had an opportunity to become slightly more familiar with the layout of the station than desired (i.e. by identifying the exit locations) and therefore be less likely to require the station signage. Thus this time delay may have influenced the need to utilise the emergency signage during the trial. 
In summary, from the video analysis the majority of the participants (99\%) utilised their nearest exit during the trial. The platform was evacuated within 45 seconds (i.e. the time for the last participant to leave the platform) with an even spread of participants using the two end exits (Exit A and Exit D) and a smaller number of participants using the central exit, Exit C. Very few participants (5\%) were observed looking up at signage during the trial.

\section{5) Results of TS2.2 from video analysis - ADSS}

Trial TS2.2 involved the use of the ADSS to direct the participants towards Exit D, according to a specific evacuation strategy, given the nature of the assumed incident. This trial was intended to assess the participant reaction to the ADSS.

The video analysis of TS2.2 involved 152 participants. Presented in Table 10 are the number of participants that started in each of the numbered boxes and then used one of the three exits (Exits A, C and D) during TS2.2. The number of participants from each box who moved to their nearest exit is highlighted in bold. Note that among the 25 participants who started in box 5 (Orange box) and used Exit D, 14 of them were initially located nearer to Exit D, while the other 11 were located nearer to Exit $\mathrm{C}$.

Table 10: Starting locations and ending exits of participants and their use of signs during TS2.2.

\begin{tabular}{|c|c|c|c|c|c|c|c|c|c|}
\hline \multirow{3}{*}{ Exit used } & \multicolumn{7}{|c|}{ Boxes and initial population size } & \multirow{2}{*}{ Total } & \multirow{3}{*}{$\begin{array}{c}\% \text { moved to } \\
\text { each exit }\end{array}$} \\
\hline & Blue/1 & Magenta/2 & Green/3 & Yellow/4 & Orange/5 & Purple/6 & White/7 & & \\
\hline & 31 & 20 & 25 & 11 & 27 & 13 & 25 & 152 & \\
\hline Exit A & 13 & 18 & 19 & 0 & 0 & 0 & 0 & 50 & $32.9 \%$ \\
\hline Exit $\mathrm{C}$ & 0 & 0 & 0 & 5 & 2 & 0 & 0 & 7 & $4.6 \%$ \\
\hline Exit D & 18 & 2 & 6 & 6 & 25 & 13 & 25 & 95 & $62.5 \%$ \\
\hline $\begin{array}{l}\text { Saw \& ignored } \\
\text { signs }\end{array}$ & 1 & 1 & 3 & 3 & 0 & 0 & 0 & 8 & - \\
\hline
\end{tabular}

There were a total of 50 participants using Exit A with the last participant exiting after 35 seconds, 7 participants used Exit $\mathrm{C}$ with the last participant exiting in 28 seconds and 95 participants used Exit D with the last participant exiting in 83 seconds. The entire platform was then cleared within 83 seconds. The time to clear the platform was longer in T2.2 compared to T2.1. To a certain extent, this is to be expected as there were more people in TS2.2 than in TS2.1. However, the increase in the number of people does not account for the increased time to clear the platform. The key difference is that a number of participants in TS2.2 did not exit via their nearest exit but exited from Exit D as instructed by the ADSS. Some participants walked the entire length of the platform (by passing other exits) before finally exiting from Exit D.

As expected, among the 52 participants whose nearest exit was Exit D (including 14 starting in box 5 (Orange), 13 in box 6 (Purple) and 25 in box 7 (White) 100\% of them used this exit during TS2.2. This is similar to the results of TS2.1, in which $99 \%$ of the entire population used their nearest exit. While it could be argued that these participants were affected by the ADSS and utilised Exit D, it could also be argued that they simply moved to their nearest exit. However, among the 100 participants whose nearest exit was Exit A or C (including 31 starting in box 1 (Blue), 20 in box 2 (Magenta), 25 in box 3 (Green), 11 in box 4 (Yellow) 
and 13 in box 5 (Orange)), only 57\% (57) of these moved to their nearest exits in TS2.2, compared with $99 \%$ in TS2.1. Thus $43 \%$ of the population whose nearest exit was Exit A or $\mathrm{C}$, did not use their nearest exit. Given that the only intended difference between the two trials was the presence of the ADSS (the 'red-cross' no entrance signs at Exit A and C, 'green arrow' entrance sign at Exit D), it is suggested that the ADSS strongly influenced route choice. It is noted that those who did not use their nearest exit (i.e. the $43 \%$ ) could have been affected by a combination of the direct impact of the ADSS directing them away from Exits $\mathrm{A}$ and $\mathrm{C}$ towards Exit $\mathrm{D}$ and the impact of simply following those who were redirecting away from their nearest exit due to perceiving the no entrance signs (a secondary effect of the ADSS). It is likely that both factors worked to reinforce the exit choice decision of those who did not use their nearest exit.

The influence of the ADSS on participant exit selection in TS2.2 is further examined for the participants started from each of the boxes.

- Box 1 (Blue): The participants started in box 1 were located at the far end of the platform; they had to travel a long distance and pass Exit $\mathrm{A}$ and $\mathrm{C}$ in order to reach the exit indicated by the ADSS, Exit D. Despite the presence of nearer exits on their way, $58 \%$ (18 out of 31 ) of these participants chose to use Exit D.

- Boxes 2 and 3 (Magenta and Green): The participants in boxes 2 and 3 were located next to Exit A. Among these participants, $10 \%$ and 29\% respectively moved to Exit D. The relatively higher proportion of people from box 1 using Exit D than those from boxes 2 and 3 may have been due to the actions of a participant starting in box 1 who decided to use Exit D and directed several others to also do so. It should also be noted that this type of response might also occur during an actual incident.

- Boxes 4 and 5 (Yellow and Orange): Among the 11 participants in box 4 and 13 participants in box 5 whose nearest exit was Exit C, 71\% (17 out of 24) used Exit D. This represents the highest proportion of participants to use Exit D whose nearest exit was not Exit D. However, these participants were closer to Exit D and the flashing green ADSS sign located above Exit D than the participants located in boxes 1,2 and 3 ; which may explain why a higher proportion of people in boxes 4 and 5 followed the ADSS to use Exit D. While the participants in boxes 1-5 received the negative information from the signs located above their nearest exits (Exits A and C), they did not necessarily perceive the positive information from the sign located above Exit D. Those located in boxes 4 and 5 were closest to Exit D and so had the greatest chance of seeing not only the negative information above their nearest exit (Exit $\mathrm{C}$ ) but also the positive information above their adjacent exit, Exit D. If correct, this suggests that to achieve the greatest compliance to the signage strategy it is necessary not only to convey negative information indicating which route not to take, but also positive information about which route is considered viable. However, the fact that participants from boxes 1-5 did move to the indicated exit rather than utilise their nearest exits suggests that the ADSS did have some effect on the evacuation of these sub-populations. 
- Boxes 6 and 7 (Purple and White): All the participants in boxes 6 and 7 used the exit indicated by the flashing green ADSS sign however, this exit also happened to be their nearest exit. So while there appears to be $100 \%$ compliance with the sign, it is not clear if this behaviour is influenced by the presence of the flashing green sign or if this would have occurred anyway due to proximity of the exit.

In total, 63\% (95 out of 152) of the entire population used Exit D indicated by the ADSS in TS2.2. This figure includes those participants initially located close to Exit D and those who were redirected to Exit D and therefore, represents the proportion of the population that followed the intended procedural intervention posed by the ADSS.

In Table 10 there is an indication of the number of people who were observed to directly look (and/or pointing) towards the signs located above their nearest exit, but then elected to move to an exit other than Exit D; i.e. those participants who saw and then ignored the negative information provided by the signs. It should again be noted that the video camera angles did not provide an opportunity to note this behaviour for the majority of the participants, so these numbers are not intended to be definitive, but indicate that some of the participants were clearly seen to observe the negated signs but either chose not to follow the negative information or did not understand the messaging. Given the high level of understanding of the messaging provided by the negated as revealed in the earlier survey, it is suggested that a lack of understanding was not the primary cause for failing to follow the negated information provided by the sign. It is suggested that those who elected not to follow the negated information did so because they did not perceive the more distant positive information provided by the flashing green arrow sign located above the distant Exit D.

Given the difficulties in establishing participant activities, the estimate of those being influenced by the ADSS should be considered conservative. The values derived from the video footage are only indicative, with more definitive results derived from the questionnaire analysis discussed in next section.

\section{6) Effectiveness of the standard static signage system and the ADSS}

In TS2.1, 99\% of the participants used their nearest exit. However, in TS2.2, 43\% of the population whose nearest exit was Exit $\mathrm{A}$ or $\mathrm{C}$, did not use their nearest exit. Considering the similarity in the recruited participants' level of familiarity and their positioning on the platform between the two trials, the use of non-nearest exit in TS2.2 is likely to be due to the presence of another influencing factor. Clearly, the ADSS used in TS2.2 was different from the standard signage system used in TS2.1. The nature of the influence of the ADSS on participants' exit selection is further analysed to determine whether the hypothesis that the ADSS influenced performance is reasonable.

In TS2.2, three negated exit signs were placed at Exits A, B and C, while one flashing arrow sign was placed at Exit D (see Figure 5). The intended procedure associated with this ADSS configuration was to direct all participants to use Exit D, in clear distinction from Trial TS2.1 where all four static signs pointed towards the nearest exits. The video analysis results show 
that among the 87 participants who were in boxes 1-4, 55 used Exits A-C, while 32 used Exit D (see Table 10). All the other participants whose nearest exit was Exit D (52\% in Box 5 and all participants in Boxes 6 and 7) used Exit D. This represents three distinctive evacuation behaviours during TS2.2, considering the participants' initial location, location of the participants nearest exit, participants exit choice and the type of signs available on their chosen route that potentially influenced their decision (see the questionnaire results in Table $11)$.

Table 11: Evacuation behaviours in the trials with available signage as a potential influencing factor.

\begin{tabular}{|c|c|c|c|c|c|c|}
\hline $\begin{array}{c}\text { Evacuation } \\
\text { behaviour }\end{array}$ & $\begin{array}{c}\text { Number of } \\
\text { participants* }\end{array}$ & $\begin{array}{c}\text { Initial } \\
\text { location }\end{array}$ & $\begin{array}{c}\text { Nearest } \\
\text { exit }\end{array}$ & $\begin{array}{c}\text { Used } \\
\text { exit }\end{array}$ & $\begin{array}{c}\text { Type of sign(s) on } \\
\text { chosen route }\end{array}$ & $\begin{array}{c}\text { Number of } \\
\text { participants noticed } \\
\text { sign(s) }\end{array}$ \\
\hline TS2.2_B1 & 59 & Box 1-4 & Exit A-C & Exit A-C & Negated exit sign & $45(76 \%)$ \\
\hline TS2.2_B2 & 31 & Box 1-4 & Exit A-C & Exit D & $\begin{array}{c}\text { Negated exit sign and } \\
\text { flashing arrow sign }\end{array}$ & $28(90 \%)$ \\
\hline TS2.2_B3 & 56 & Box 5-7 & Exit D & Exit D & Flashing arrow sign & $50(89 \%)$ \\
\hline TS2.1_B4 & 149 & Box 1-7 & Exit A-D & Exit A-D & Standard static sign & $118(79 \%)$ \\
\hline
\end{tabular}

* A few participants from TS2.2 were not included in this table because they started in Box 5-7 and claimed they used Exit A. From the video analysis, no one from these boxes did so (see Table 10); therefore, an error is assumed.

Behaviour TS2.2_B1 represents those participants who were nearest to Exit A-C and used them in TS2.2. Behaviour TS2.2_B3 represents those participants who were nearest to Exit D and used it in TS2.2. In both cases, it is possible that these participants were only exposed to one type of sign: either the negated exit signs (with no additional indication in close proximity identifying a usable exit, leaving participants to use their nearest exit) or the flashing arrow sign. Behaviour TS2.2_B2 includes those participants whose nearest exit was Exit A-C, but chose to evacuate via Exit D in TS2.2. It was likely that they were influenced either directly or indirectly by both the negated exit signs above their nearest exit and the flashing arrow sign indicating the use of Exit D. In order to compare TS2.2 with TS2.1, a fourth behaviour TS2.1_B4 is added to Table 11 to represent the participants in TS2.1 and their evacuation behaviour; they used their nearest exit and only the standard exit signs were available and were a potential influencing factor. Presented in Table 12 are the responses provided by the trial participants to a question requesting that they identify the factors that influenced their exit selection during the trial. The question allowed participants to select multiple answers from a list of options and allowed them to enter additional factors. Their response was then normalised to determine their relative significance. Each participant's answer score was normalised as follows:

1. If the participant selected only one option, this option scored a value of one; i.e. the identified factor fully influences the participant's response.

2. If the participant selected multiple options, each selected option was given an equal fractional score, the total score equalling one. Thus if three options were selected, each option was given a score of $1 / 3$.

To determine the overall score for the option, the score provided by each person was summed and the total divided by the number of replies to provide an indication of the relative significance of the factor for the population as a whole. 
In behaviour TS2.1_B4, where almost all participants used their nearest exit, 79\% (118 out of 149) of the participants claimed to have noticed the emergency exit signs. However, signage only accounted for $26.8 \%$ in their exit selection, followed by the influence of surrounding participants which accounted for $18.0 \%$; while the most significant factor $(50.7 \%)$ was that there was an immediate exit next to them (see Table 12). These results suggest that in TS2.1 although most of the participants were aware of the standard static signs as a source of information, the signs played a minor role in their exit selection with proximity to exit being the most significant. Therefore, in TS2.1 where people used their nearest exit, the information provided by the signs was not the dominant influence on exit selection.

Table 12: Relative significance of the impact of factors upon participant exit selection during the trials based on questionnaire data.

\begin{tabular}{|c|c|c|c|c|}
\hline Evacuation behaviour & Surrounding participants & Presence of a nearest exit & Signage & Others \\
\hline TS2.2_B1 & $24.6 \%$ & $46.7 \%$ & $20.4 \%$ & $8.3 \%$ \\
\hline TS2.2_B2 & $14.5 \%$ & $12.9 \%$ & $71.0 \%$ & $1.6 \%$ \\
\hline TS2.2_B3 & $13.4 \%$ & $43.8 \%$ & $39.6 \%$ & $3.2 \%$ \\
\hline TS2.1_B4 & $18.0 \%$ & $50.7 \%$ & $26.8 \%$ & $4.5 \%$ \\
\hline
\end{tabular}

In behaviour TS2.2_B1, where participants used their nearest exit, contradicting the information provided by the negated exit dynamic signs, $76 \%$ (45 out of 59) of the participants claimed to have noticed the emergency exit signs. However, similar to TS2.1_B4, signage accounted for only $20.4 \%$ in influencing their exit selection, while the most significant factor $(46.7 \%$ ) was proximity to an exit (see Table 12), again similar to TS2.1_B4. Indeed, the participants of TS2.2_B1 behaved similarly as those in TS2.1_B4; they all used their nearest exits and primarily for the same reason: they predominantly chose their nearest exit rather than utilising the signs. The neglecting of the signage information and the relatively low significance of signage as a source of information to the participants in pattern TS2.2_B1 can be explained by the positioning of the negated exit signs in TS2.2. As indicated previously, these negated exit signs provided negative signage information to the participants whose nearest exits were Exit A-C, but did not then indicate a viable alternative. These participants may then have had no other viable exit suggested, as the only positive sign was located at Exit D and, given the distance and incident angle it might not have been noticed. As a result, the negated exit signs became less important than the proximity to an exit in exit selection among the participants exhibiting behaviour TS2.2_B1. These results suggest that while the participants exhibiting behaviour TS2.2_B1 may have perceived the negated exit sign, they did not perceive the flashing green arrow sign further down the platform and so had no other viable option than to use their nearest exit. Therefore, when participants made use of their nearest exit against the advice of the ADSS (red cross) the information provided by the signs may have been only partially successful in alerting the participants that the exit was not viable, but not providing them with an alternative.- This 


\section{then reflects the importance of providing positive information if negative information is provided by the sign.}

In behaviour TS2.2_B2, where participants used Exit D even though it was not their nearest exit, $90 \%$ (28 out of 31) of the participants claimed to have noticed the emergency exit signs. This is much higher than those who claim to have noted the signs in TS2.2_B1 and TS2.1_B4 where the signs did not play a significant role in exit selection. Note not only do a significant proportion claim to have seen the sign, but also in this case signage accounted for $71.0 \%$ in influencing their exit selection, while the presence of the nearest exit (previously the most significant factor in TS2.2_B1 and TS2.1_B4) only accounted for 12.9\% (see Table 12). This suggests that signage played a much more important role in behaviour TS2.2_B2 than TS2.2_B1 and TS2.1_B4. In addition, considering the influence of surrounding participants accounted for $14.5 \%$, it is possible that some participants were following others who had already been influenced by the ADSS; i.e. the signs had a secondary effect on their exit selection. In effect, the actual relative significance of signage might then be higher than $71 \%$. These results can be interpreted to suggest that the participants in TS2.2_B2 established from the no entrance signs that their nearest Exit A-C should not be used (saw the negated sign) and then they followed the flashing arrow sign to use Exit D (saw the positive sign); i.e. they perceived both the no entrance signs and flashing arrow sign and they treated signage as single important factor in their exit selection. In essence, these participants had access to the full set of the procedural information available.

In behaviour TS2.2_B3, the participants used Exit D, which was their nearest exit, which was also indicated by the flashing arrow sign above it. In this case 89\% (50 out of 56) of the participants claimed to have noticed the emergency exit sign. The questionnaire results show that signage accounted for $39.6 \%$ in their exit selection. This is lower than the influence during TS2.2_B2 (71.0\%), but double that evident in TS2.2_B1 (20.4\%). It should also be noticed that the presence of the nearest exit accounted for $43.8 \%$, which is comparable to the relative significance of signage. These results suggest that most participants in exhibiting behaviour TS2.2_B3 perceived the flashing arrow sign and they treated the signage and proximity of the exit almost equally in their exit selection. This suggests that it would not be unreasonable to state that those located nearest to Exit D who went on to use this exit were also influenced by the presence of the flashing green sign, not simply their proximity to the exit. Thus unlike the presence of the standard static signs in TS2.1, the presence of the flashing green arrow sign had at least an equivalent impact on participant exit selection as the proximity of the exits in TS2.2. In summary, analysis of the four behaviours exhibited by participants in these trials suggests that:

- In situation where the standard signage is used, while participants were generally aware of the signage, they typically moved towards their nearest exit independently of the signage (TS2.1_B4).

- The ADSS had a more direct and prominent impact than the standard signs influencing the behaviour of the participants in three ways:

$\circ$ When only negative signage information was available, while the negated exit signs conveyed to the participants that the exit was not appropriate to use, the 
absence of positive information indicating a viable alternative meant that the participants discarded the signage information and selected their nearest exit (TS2.2_B1). Negative information alone is insufficient to guide the participants, and may lead to confusion if no other information is readily available, highlighting the importance of appropriate positioning of signs.

- When both negative and positive signage information was perceived, signage had a dominant impact on participant exit selection, guiding them to move in accordance with the intended procedure; i.e. use the intended exit; the negative information discouraged them from using their nearest exit and the positive information encouraged them to use the specified exit (TS2.2_B2).

$\circ$ When only positive information is perceived, the flashing arrow sign reinforced the decision to use the nearest exit (TS2.2_B3).

It was also found through the questionnaire analysis that $65.6 \%$ of the participants who saw at least one of the ADSS signs stated that the flashing lights in the arrows assisted them in selecting which way to go. Furthermore, $61.5 \%$ of the population agreed that the flashing lights in the arrow assisted them in making a quick decision. In addition, 51.0\% agreed that the flashing red cross indicated which exit should not be used. These results demonstrate that the ADSS offers significant advantage to standard signs, even though the flashing lights did not present both positive and negative information at the same place.

In the evacuation trial involving the ADSS, the majority of participants (63\%) followed the intended evacuation procedure and utilised the intended target exit, without staff intervention. It is suggested that the percentage of people following the intended evacuation procedure could have been improved had both negative and positive information (precluding the use of some exits and encouraging the use of others) been available at each decision point. This is demonstrated by those participants that had access to both the negative and positive information (those participants initially located in boxes 4 and 5 and near Exit C); for these participants the proportion using the intended target exit even though they were initially closer to another exit was $71 \%$. Where incomplete signage information was provided, while the participants (those initially located in boxes 1, 2, 3 and near Exit A and Exit B) demonstrated that they understood the meaning of the negated exit sign, many elected to use their nearest exit regardless. This was an issue of signage positioning and information completeness rather than the effectiveness of the ADSS concept.

\section{7) Limitations}

As with any experimental project there were several procedural and methodological challenges that arose during the performance of the trials. These limitations should be taken into consideration when reviewing the results.

- Fewer than expected people took part in the trials. The actual population densities achieved during the two trials were 1.4 persons $/ \mathrm{m}^{2}$ and 1.5 persons $/ \mathrm{m}^{2}$ respectively. This fell short of the desired population densities $\left(2\right.$ persons $\left./ \mathrm{m}^{2}\right)$ which was intended 
to reflect a busy station platform. This also had the effect of reducing the number of data-points produced for estimating the effectiveness of the signage systems.

- It was difficult to isolate the impact of the signage systems upon route selection from other environmental and social factors, making it impossible to obtain an estimation of the impact of signage systems alone. The attempted solution was to examine the difference in people's escape behaviour under the influence of two signage systems; i.e. had the standard signage system been replaced by the ADSS, how efficient a particular evacuation strategy can be implemented.

- Height and placement restrictions in positioning the cameras made it difficult to attain ideal monitoring of the population during the trials. This resulted in gaps in the video coverage of the trial area and the difficulty in establishing the interaction between the participants and the signage on the video footage (e.g. some cameras only showed the back of the participants). This made it necessary to rely on questionnaire results to analyse the impact of signage systems. Although the participants were required to complete the questionnaire immediately after the trials, the answers may be subject to incorrect recollection of their experiences.

- The questionnaire was formed from a set of 12 high-level closed questions, leading to more probing (although still closed) sub-questions in several instances. By their nature, closed questionnaires only allow the researcher to ask the participant to select between pre-determined responses.

- Given the nature of the trials, the original English-language version of the questionnaire had to be translated in Spanish and Catalan. This meant that there was an additional distance between the original question design and the intended meaning as mediated by the translation process. Where this is suspected to have affected the results collected, such as in the 'group' question, the concern has been highlighted.

- The volunteers were selected so that they had little or no prior knowledge of the station layout, removing familiarity with the layout as a factor influencing exiting behaviour. Thus the vast majority of participants in the trial were unfamiliar with the layout of the station, with about $44 \%$ never having been to the station before and another $46 \%$ having been to the station less than once or twice per month. Thus the trial results only apply to people who are relatively unfamiliar with the layout. It is not clear whether or not the dynamic signage would have been as effective with a population of habitual users of the station.

\section{CONCLUSIONS}

As part of the EU FP7 GETAWAY project, a unique and innovative signage system, known as the Active Dynamic Signage System (ADSS) has been developed that is intended to direct building occupants away from non-viable exit routes and lead them to a safe exit. The ADSS concept involves incorporating two novel signage designs into the standard green running man emergency exit sign: a means to attract the attention of building occupants and a means to identify that a previously viable exit route is no longer considered viable. To attract the 
attention of the building occupants involves incorporating a green flashing and running arrow into the exit sign. Previous work has demonstrated that this approach can be very effective in attracting attention to the sign. However, a means to negate an exit route needed to be developed which was relatively easy to fit within the standard exit sign concept, was intuitive making it easy to understand without requiring instruction and which would fail safe should it fail to operate.

Four negated signage concepts were suggested and tested via an international survey involving more than 600 participants. The results demonstrate that a simple red cross passing through the entire sign can be correctly interpreted by over $90 \%$ of the sample as indicating that the exit route is no longer considered viable and so should not be used. The negation concept was built into the ADSS and the entire concept was tested in two full scale evacuation trials performed at a railway station in Barcelona involving 139 and 152 volunteer participants respectively. The volunteers were selected so that they had little or no prior knowledge of the station layout, removing familiarity with the layout as a factor influencing exiting behaviour. The aim of the trials was to assess the effectiveness of the ADSS in comparison with the current standard emergency signage system. The trial took place on a long rail platform from which there were four exits labelled A, B, C and D.

The first trial was conducted to establish a baseline response to standard static emergency exit signage. The results of the trial showed that $99 \%$ of the 139 participants exited the station using their nearest exit. Although the participants' exit selection was consistent with the emergency signage which pointed directly towards the nearest exits, only a small number of participants were identified in video footage as actively looking at the emergency exit signs suggesting that the choice of these exits routes was unlikely to be influenced by the presence of the signs. This was confirmed by the results of the questionnaire which indicated that proximity to the exit was the most influential factor in selecting an exit and this was almost twice as influential as signage.

The second trial aimed to assess the participant reaction to the ADSS, which was configured to direct all 152 participants away from the first three exits (A, B and C) towards Exit D located at one end of the platform. This was not the nearest exit for the majority of the population and therefore required the population to adopt a different behaviour from that exhibited in the first trial. When the alarm was sounded the ADSS above each exit was activated, with the first three exits having a negated exit sign located above the exit and Exit D having a flashing green arrow exit sign located above the exit. The results of the trial showed that $63 \%$ of the total population used the target exit; i.e. followed the intended procedure posed by the ADSS. This included those drawn to the exit and those initially located nearest to it. Furthermore, $43 \%$ of the participants whose nearest exit was not the target exit were redirected to the indicated exit. It was also noted that the impact of the ADSS was not uniform across the entire platform, with participants whose nearest exit was Exit $\mathrm{C}$, reacting best to the ADSS, having some $71 \%$ of these participants ignoring their nearest exit and electing to use Exit D. It was suggested that the participants in the vicinity of Exit $\mathrm{C}$ reacted best to the ADSS as they had easy access of both the negative information 
i.e. don't use this exit, and the positive information i.e. use this exit. This was due to their relative proximity to Exit D. Participants located near Exit A and Exit B, while able to perceive the negative information could not easily perceive the positive information. These conclusions were confirmed through analysis of the participant questionnaire data.

The main conclusion of these trials is that the ADSS was influential in participant exit route choice and was capable of directing a large proportion of the building population towards a distant target exit and away from closer (non-viable) exits. The ADSS concept therefore addresses a significant weakness of conventional signage systems by providing emergency signage with a means to adapt their guidance according to the developing hazard environment. However, to improve the efficiency of the ADSS it is important to provide positive exit route information when negative information is provided. In a latter paper additional results will be presented that demonstrate the effectiveness of incorporating both positive and negative information within the ADSS, including a faster than real time means to automatically identify the optimal exit route within a building and using this information to configure the ADSS.

\section{ACKNOWLEDGEMENT}

Project GETAWAY (contract 265717) was funded under the European Union Framework 7 Transport initiative. The authors acknowledge the co-operation of their project partners: BMT, Vision Semantics Ltd, London Underground Ltd, Evaclite Ltd, Hochiki Europe, Kingfell Bulgaria and FGC Spain; in undertaking this work and in allowing the project findings to be published. The authors are particularly grateful to FGC for allowing the use of two of their railway stations on two days.

\section{REFERENCES}

1. Sime, J.D., 1985. Movement Towards the Familiar - Person and Place Affiliation in a Fire Entrapment Setting, Environment and Behaviour, 17(6): 697-724, doi:10.1177/0013916585176003.

2. Shields T.J. and Boyce K.E., 2000. A Study of Evacuation from Large Retail Stores, Fire Safety Journal 35, 2000, 25-49. doi:10.1016/S0379-7112(00)00013-8.

3. Nilsson, D., Frantzich, H., Saunders, W., 2008. Influencing Exit Choice in the Event of a Fire Evacuation., Fire Safety Science - Proceedings of the ninth Symposium, IAFSS, 2008, pp 341-352. http://dx.doi.org/10.3801/IAFSS.FSS.9-341.

4. Xie, H., Filippidis, L., Galea, E.R., Blackshields, D., Lawrence, P.J., 2012. Experimental analysis of the effectiveness of emergency signage and its implementation in evacuation simulation, Fire and Materials, Vol 36, pp367-382. http://dx.doi.org/10.1002/fam.1095 
5. K. Fridolf, D. Nilsson and H. Frantzich, 2013. Fire evacuation in underground transportation systems: a review of accidents and empirical research, Fire Technology, 49, 451-475, 2013, DOI: 10.1007/s10694-011-0217-x

6. GETAWAY (Generating simulations to Enable Testing of Alternative routes to improve WAYfinding in evacuation of overground and underground terminals), project grant agreement, THEME SST.2010.4.1-1, EU FP7, grant agreement 265717, 07/07/11.

7. http://fseg.gre.ac.uk/fire/GETAWAY.html

8. Galea, E., Wang, Z., Veeraswamy, A., Jia, F., Lawrence, P., and Ewer, J., 2009. Coupled Fire/Evacuation Analysis of the Station Nightclub Fire, Proc IAFSS $9^{\text {th }}$ Syp: 465-476, http://dx.doi.org/10.3801/IAFSS.FSS.9-465

9. Jin, T., Yamada, T., Kawai, S. and Takahashi, S., 1991. Evaluation Of The Conspicuousness Of Emergency Exit Signs. Fire Safety Science 3: 835-841. doi:10.3801/IAFSS.FSS.3-835

10. Nilsson, D., Frantzich, H., \& Saunders, W., 2005. Coloured Flashing Lights to Mark Emergency Exits - Experiences from Evacuation Experiments. Fire Safety Science Proceedings of the Eighth International Symposium, International Association of Fire Safety Science, pp 569-579.

11. Nilsson, D., Frantzich, H., \& Saunders, W., 2008. Influencing Exit Choice in the Event of a Fire Evacuation. Fire Safety Science - Proceedings of the Ninth International Symposium, International Association of Fire Safety Science, pp 341-352. DOI:10.3801/IAFSS.FSS.9-341.

12. Enrico Ronchi, Daniel Nilsson, 2015. A Virtual Reality experiment on the design of flashing lights at emergency exit portals for road tunnel evacuations. Lund University Report, Report 3180, 2015.

13. Emília Duarte, Francisco Rebelo, Júlia Teles, Michael S. Wogalter, 2014. Behavioral compliance for dynamic versus static signs in an immersive virtual environment., Applied Ergonomics, Vol 45, pp 1367-1375, http://dx.doi.org/10.1016/j.apergo.2013.10.004

14. Gibson, J.J., The Ecological Approach to Visual Perception, Houghton Mifflin Company, Boston, 1978.

15. Directive 92/58/EEC - safety and/or health signs

16. EN ISO 7010 Graphical symbols - Safety colours and safety signs - Registered safety signs (ISO 7010:2011)

17. Xie, H., Galea, E.R., and Lawrence, P.J., 2013. Experimental Study of the Effectiveness of Dynamic Signage System", Proceedings of the 13th International Fire Science \& Engineering Conference, Interflam 24-26th June 2013, Royal Holloway College, London, UK, Volume 2, pp. 967-978. ISBN 9780 9556548-9-3, 2013. 
18. Galea E.R., Xie, H., and Lawrence, P.J., 2014., "Experimental and Survey Studies on the Effectiveness of Dynamic Signage Systems", Fire Safety Science, Proceedings of the $11^{\text {th }}$ International Symposium, IAFSS, pp. 1129-1143, 2014, IAFSS / DOI: 10.3801/IAFSS.FSS.11-1129

19. Galea E.R., Xie, H., and Lawrence, P.J., Experimental Analysis of the Effectiveness of Dynamic Signage and its Implementation in Evacuation Simulation. In preparation. 
Table 1: Profession, age and country of the respondents.

\begin{tabular}{|c|c|c|c|c|c|c|c|c|c|c|c|c|}
\hline \multirow{2}{*}{$\begin{array}{l}\text { Data-Set* } \\
\text { (number) }\end{array}$} & \multicolumn{2}{|c|}{ Profession } & \multicolumn{3}{|c|}{ Age } & \multicolumn{7}{|c|}{ Country } \\
\hline & Fire Prof & $\begin{array}{c}\text { Non-fire } \\
\text { Prof }\end{array}$ & $\begin{array}{c}\text { Age } \\
15-25 \\
\end{array}$ & $\begin{array}{c}\text { Age } \\
26-50\end{array}$ & $\begin{array}{c}\text { Age } \\
51-75\end{array}$ & UK & Germany & France & Italy & China & USA & Others \\
\hline $\begin{array}{c}\text { Preliminary } \\
(457)\end{array}$ & $\begin{array}{c}246 \\
(54 \%)\end{array}$ & $\begin{array}{c}206 \\
(45 \%)\end{array}$ & $\begin{array}{c}139 \\
(30 \%) \\
\end{array}$ & $\begin{array}{c}212 \\
(46 \%)\end{array}$ & $\begin{array}{c}99 \\
(22 \%)\end{array}$ & $\begin{array}{c}143 \\
(31 \%)\end{array}$ & $\begin{array}{c}94 \\
(21 \%)\end{array}$ & $\begin{array}{c}26 \\
(6 \%)\end{array}$ & $\begin{array}{c}21 \\
(5 \%) \\
\end{array}$ & $\begin{array}{c}40 \\
(9 \%)\end{array}$ & $\begin{array}{c}70 \\
(15 \%)\end{array}$ & $\begin{array}{c}63 \\
(14 \%) \\
\end{array}$ \\
\hline $\begin{array}{c}\text { Complete } \\
\text { (613) }\end{array}$ & $\begin{array}{c}322 \\
(53 \%)\end{array}$ & $\begin{array}{c}286 \\
(47 \%)\end{array}$ & $\begin{array}{c}176 \\
(29 \%)\end{array}$ & $\begin{array}{c}298 \\
(49 \%)\end{array}$ & $\begin{array}{c}132 \\
(22 \%)\end{array}$ & $\begin{array}{c}203 \\
(33 \%)\end{array}$ & $\begin{array}{c}119 \\
(19 \%)\end{array}$ & $\begin{array}{c}32 \\
(5 \%)\end{array}$ & $\begin{array}{c}41 \\
(7 \%)\end{array}$ & $\begin{array}{c}43 \\
(7 \%)\end{array}$ & $\begin{array}{c}82 \\
(13 \%)\end{array}$ & $\begin{array}{c}93 \\
(15 \%)\end{array}$ \\
\hline
\end{tabular}

$*$ Not everyone answered all questions. 
Table 2: Percentage of respondents who correctly interpreted meaning of signs.

\begin{tabular}{|c|c|c|c|}
\hline Exit signs based on negated signage design & Fire safety profession & Other professions & Total \\
\hline exit & $\begin{array}{c}83 \% \\
(312 \text { total })\end{array}$ & $\begin{array}{c}85 \% \\
(275 \text { total })\end{array}$ & $\begin{array}{c}84 \% \\
(587 \text { total })\end{array}$ \\
\hline Fire & $\begin{array}{c}63 \% \\
(311 \text { total })\end{array}$ & $\begin{array}{c}52 \% \\
(268 \text { total })\end{array}$ & $\begin{array}{c}58 \% \\
(579 \text { total })\end{array}$ \\
\hline S3 & $\begin{array}{c}92 \% \\
(311 \text { total })\end{array}$ & $\begin{array}{c}92 \% \\
(270 \text { total })\end{array}$ & $\begin{array}{c}(581 \text { total }) \\
7\end{array}$ \\
\hline
\end{tabular}


Table 3: Respondents' level of agreement with the statement regarding the intended meaning of the negated signs.

\begin{tabular}{|c|c|c|}
\hline Exit signs based on negated signage design & Agree & Disagree \\
\hline Fire & $\mathbf{5 3 \%}$ & $\mathbf{3 8 \%}$ \\
exit & $\begin{array}{c}\text { (17\% strongly agree and } \\
36 \% \text { agree })\end{array}$ & $\begin{array}{c}\text { (14\% strongly disagree and } 24 \% \\
\text { disagree })\end{array}$ \\
\hline exit & $\mathbf{4 3 \%}$ & $\begin{array}{c}\mathbf{4 2 \%} \\
\text { (15\% strongly disagree and } \\
27 \% \text { disagree })\end{array}$ \\
\hline \\
\hline
\end{tabular}


Table 4: Percentage of respondents who identified which one of the four negated signs best denoted the concept that the exit route was no longer viable.

\begin{tabular}{|c|c|}
\hline Exit signs based on negated signage design & Percentage of population \\
\hline & $\mathbf{7 \%}$ \\
\hline F1 exit & $(41)$ \\
\hline & $\mathbf{3 \%}$ \\
\hline & Fire \\
\hline
\end{tabular}


Table 5: Age distribution of trial participants and the intended age distribution.

\begin{tabular}{|c|c|c|c|c|c|}
\hline \multirow{2}{*}{ Age } & \multicolumn{2}{|l|}{ TS2.1 } & \multicolumn{2}{|l|}{ TS2.2 } & \multirow{2}{*}{$\begin{array}{l}\text { Intended age } \\
\text { distribution }\end{array}$} \\
\hline & Number of participants & Percentage & Number of participants & Percentage & \\
\hline $18-20$ & 11 & $7.4 \%$ & 5 & $3.3 \%$ & $10 \%$ \\
\hline $20-29$ & 39 & $26.2 \%$ & 43 & $28.3 \%$ & $20 \%$ \\
\hline $30-49$ & 69 & $46.3 \%$ & 78 & $51.3 \%$ & $45 \%$ \\
\hline $50-59$ & 16 & $10.7 \%$ & 18 & $11.8 \%$ & $15 \%$ \\
\hline$>=60$ & 14 & $9.4 \%$ & 8 & $5.3 \%$ & $10 \%$ \\
\hline Total & 149 & $100.0 \%$ & 152 & $100.0 \%$ & $100 \%$ \\
\hline
\end{tabular}


Table 6: Gender distribution of trial participants and the intended gender distribution.

\begin{tabular}{|c|c|c|c|c|c|}
\hline \multirow{2}{*}{ Gender } & \multicolumn{2}{|l|}{ TS2.1 } & \multicolumn{2}{|l|}{ TS2.2 } & \multirow{2}{*}{$\begin{array}{c}\text { Intended gender } \\
\text { distribution }\end{array}$} \\
\hline & Number of participants & Percentage & Number of participants & Percentage & \\
\hline Male & 74 & $49.7 \%$ & 84 & $55.3 \%$ & $55 \%$ \\
\hline Female & 75 & $50.3 \%$ & 68 & $44.7 \%$ & $45 \%$ \\
\hline Total & 149 & $100.0 \%$ & 152 & $100.0 \%$ & $100 \%$ \\
\hline
\end{tabular}


Table 7: Participant familiarity with the trial geometry.

\begin{tabular}{|c|c|c|c|c|}
\hline \multirow{2}{*}{ Frequency } & \multicolumn{2}{|c|}{ TS2.1 } & \multicolumn{2}{c|}{ TS2.2 } \\
\cline { 2 - 5 } & Number of participants & Percentage & Number of participants & Percentage \\
\hline Never & 66 & $44.3 \%$ & 68 & $44.7 \%$ \\
\hline $1-7$ days/week & 5 & $3.4 \%$ & 6 & $3.9 \%$ \\
\hline 1 or 2/month & 11 & $7.4 \%$ & 6 & $4.9 \%$ \\
\hline $\begin{array}{c}\text { Infrequently (i.e. less than } \\
1 \text { or 2/month) }\end{array}$ & 67 & $45.0 \%$ & 72 & $100.0 \%$ \\
\hline Total & 149 & $100.0 \%$ & 152 & $47.4 \%$ \\
\hline
\end{tabular}


Table 8: The numbers of unfamiliar and familiar participants positioned in the seven boxes in the trials.

\begin{tabular}{|c|c|c|c|c|c|c|c|c|c|}
\hline \multicolumn{2}{|c|}{} & Blue/1 & Magenta/2 & Green/3 & Yellow/4 & Orange/5 & Purple/6 & White/7 & Total \\
\hline \multirow{2}{*}{ TS2.1 } & Unfamiliar & 8 & 9 & 10 & 10 & 9 & 11 & 9 & \multirow{2}{*}{149} \\
\cline { 2 - 10 } & Familiar & 16 & 4 & 18 & 8 & 16 & 4 & 17 & \\
\hline \multirow{2}{*}{ TS2.2 } & Unfamiliar & 10 & 8 & 11 & 5 & 15 & 6 & 13 & \multirow{2}{*}{152} \\
\cline { 2 - 10 } & Familiar & 21 & 13 & 14 & 6 & 12 & 7 & 11 & \\
\hline
\end{tabular}


Table 9: Starting and ending locations of participants during TS2.1.

\begin{tabular}{|c|c|c|c|c|c|c|c|c|c|}
\hline \multirow{2}{*}{ Exit used } & \multicolumn{7}{|c|}{ Boxes and initial population size } & \multirow{2}{*}{ Total } & \multirow{2}{*}{$\begin{array}{c}\text { moved to } \\
\text { each exit }\end{array}$} \\
\cline { 2 - 10 } & Blue/1 & Magenta/2 & Green/3 & Yellow/4 & Orange/5 & Purple/6 & White/7 & \\
\cline { 2 - 9 } & 21 & 12 & 24 & 19 & 26 & 14 & 23 & 139 & \\
\hline Exit A & $\mathbf{2 1}$ & $\mathbf{1 2}$ & $\mathbf{2 3}$ & 0 & 0 & 0 & 0 & 56 & $40.3 \%$ \\
\hline Exit C & 0 & 0 & $\mathbf{1}$ & $\mathbf{1 7}$ & $\mathbf{5}$ & 0 & 0 & 23 & $16.5 \%$ \\
\hline Exit D & 0 & 0 & 0 & 2 & $\mathbf{2 1}$ & $\mathbf{1 4}$ & $\mathbf{2 3}$ & 60 & $43.2 \%$ \\
\hline
\end{tabular}


Table 10: Starting locations and ending exits of participants and their use of signs during TS2.2.

\begin{tabular}{|c|c|c|c|c|c|c|c|c|c|}
\hline \multirow{2}{*}{ Exit used } & \multicolumn{7}{|c|}{ Boxes and initial population size } & \multirow{2}{*}{ Total } & \multirow{2}{*}{$\begin{array}{c}\text { moved to } \\
\text { each exit }\end{array}$} \\
\cline { 2 - 10 } & Blue/1 & Magenta/2 & Green/3 & Yellow/4 & Orange/5 & Purple/6 & White/7 & 152 & \\
\hline Exit A & $\mathbf{1 3}$ & 20 & 25 & 11 & 27 & 13 & 25 & 15 & 0 \\
\hline Exit C & 0 & 0 & $\mathbf{1 9}$ & 0 & 0 & 0 & 0 & 50 & $32.9 \%$ \\
\hline Exit D & 18 & 2 & 6 & 6 & $\mathbf{2 5}$ & $\mathbf{1 3}$ & $\mathbf{2 5}$ & 95 & $62.5 \%$ \\
\hline $\begin{array}{c}\text { Saw \& ignored } \\
\text { signs }\end{array}$ & 1 & 1 & 3 & 3 & 0 & 0 & 0 & 8 & - \\
\hline
\end{tabular}


Table 11: Evacuation behaviours in the trials with available signage as a potential influencing factor.

\begin{tabular}{|c|c|c|c|c|c|c|}
\hline $\begin{array}{c}\text { Evacuation } \\
\text { behaviour }\end{array}$ & $\begin{array}{c}\text { Number of } \\
\text { participants* }\end{array}$ & $\begin{array}{c}\text { Initial } \\
\text { location }\end{array}$ & $\begin{array}{c}\text { Nearest } \\
\text { exit }\end{array}$ & $\begin{array}{c}\text { Used } \\
\text { exit }\end{array}$ & $\begin{array}{c}\text { Type of sign(s) on } \\
\text { chosen route }\end{array}$ & $\begin{array}{c}\text { Number of } \\
\text { participants noticed } \\
\text { sign(s) }\end{array}$ \\
\hline TS2.2_B1 & 59 & Box 1-4 & Exit A-C & Exit A-C & Negated exit sign & $45(76 \%)$ \\
\hline TS2.2_B2 & 31 & Box 1-4 & Exit A-C & Exit D & $\begin{array}{c}\text { Negated exit sign and } \\
\text { flashing arrow sign }\end{array}$ & $28(90 \%)$ \\
\hline TS2.2_B3 & 56 & Box 5-7 & Exit D & Exit D & Flashing arrow sign & $50(89 \%)$ \\
\hline TS2.1_B4 & 149 & Box 1-7 & Exit A-D & Exit A-D & Standard static sign & $118(79 \%)$ \\
\hline
\end{tabular}

* A few participants from TS2.2 were not included in this table because they started in Box 5-7 and claimed they used Exit A. From the video analysis, no one from these boxes did so (see Table 10); therefore, an error is assumed. 
Table 12: Relative significance of the impact of factors upon participant exit selection during the trials based on questionnaire data.

\begin{tabular}{|c|c|c|c|c|}
\hline Evacuation behaviour & Surrounding participants & Presence of a nearest exit & Signage & Others \\
\hline TS2.2_B1 & $24.6 \%$ & $46.7 \%$ & $20.4 \%$ & $8.3 \%$ \\
\hline TS2.2_B2 & $14.5 \%$ & $12.9 \%$ & $71.0 \%$ & $1.6 \%$ \\
\hline TS2.2_B3 & $13.4 \%$ & $43.8 \%$ & $39.6 \%$ & $3.2 \%$ \\
\hline TS2.1_B4 & $18.0 \%$ & $50.7 \%$ & $26.8 \%$ & $4.5 \%$ \\
\hline
\end{tabular}

